the value of a biological outlook to the school-child applies a fortiori to the adult. But here again, extramural university teaching is largely bound up with the Workers' Educational Association. This excellent educational organisation, however, is hampered by the constitutional custom that the adult students ask for whatever classes they feel they want. As a result, adult education has come to be looked on as largely a development of the Faculty of Arts. The grown-ups ask for subjects such as psychology and economics, that naturally appear to them to bear directly upon their own lives. They do not realize that the subjects they choose are, as often as not, far beyond their mental capacity; in fact, as some of us think, they are beyond the capacity of the ordinary undergraduate. If they could be encouraged to study in a simple and broad manner the elements of biology, then a great step forward could be made in education generally.

\section{CHROMATOGRAPHY FOR GENERAL CHEMICAL ANALYSIS}

$\mathrm{O}$ RIGINALLY used for coloured substances chromatography has been extended to deal with a wide range of colourless materials, by the use of suitable coloured derivatives or of indicators. Sugars and related substances form an important class of this kind, for which chromatography has proved to be a powerful analytical tool, particularly within the last ten years.

Messrs. Binkley and Wolfram* have themselves made important contributions to the subject, and their pamphlet appears at an appropriate time, when work in this field is expanding so rapidly ; it provides carbohydrate investigators with an up-to-date historical review and practical details of the techniques involved. The first section of this pamphlet gives a simple general description of the adsorption chromatogram, with various details, such as selection of adsorbents, construction and operation of the chromatogram and location of zones after development. The second section provides a comprehensive review of the literature up to the end of 1947. Most of this section deals, of course, with adsorption chromatography, since it is only very recently that partition chromatography, particularly on paper, has been applied to the sugars. The third section describes with experimental details some of the applications of chromatography to sugars; for example, resolution and quantitative estimation of mixtures, purification, control in the production of technical sugar products and end-group assay.

Similar in size and presentation, "Introductory Notes on Chromatography" $\uparrow$ covers a much wider field, including vitamins, alkaloids, chlorophylls, carotenoids, vegetable and mineral oils, aminoacids, inorganic ions and many other substances. Some of the applications are given detailed treatment in order to illustrate methods suitable for use in analogous cases. A useful list of references is given, most of which occur within the last ten years, and, as in the case of the first pamphlet, most of the chromatography described is of the adsorption type. This pamphlet succeeds in condensing a great deal of "“Chromatography of Sugars and Related Substances," by W. W.
Binkley and M. L. Wolfram. (Scientiflc Report Series No. 10. Sugar Binkley and M. L. Wolfram. (Scientiflc
Research Foundation, Inc., New York.)

Research Foundation, Inc., New York.) $\dagger$ '.'Introducto
Ltd., Poole.) information into its forty pages and will be found useful as an introduction to the well-known text. books on chromatography.

Workers in both academic and industrial fields will find information of value in these two pamphlets, which are clearly written and attractively produced. Those who have not already adopted chromatographic techniques will be encouraged to do so after reading them. Chromatography may well prove to be indispensable in many investigations.

During the past year, the range of separations has been greatly widened by the partition chromatogram and by chromatograms which are neither clearly adsorption nor partition. Among recent advances in chromatography may be mentioned the use of dinitrophenyl derivatives of amino-acids and pep. tides, the use of radioactive isotopes, and the employ. ment of new kinds of supporting media or modifi. cations of existing media in partition chromatograms for the purpose of dealing with non-aqueous solvent systems. The present period is thus one of rapid development, and it is therefore desirable that information on the most recent advances in chromatography should be made available from time to time and with little delay. Perhaps this information might be issued in the form of pamphlets similar to those reviewed here.

R. CONSDFN

\section{NEW CHEMICAL LABORATORIES AT UNIVERSITY COLLEGE, DUBLIN}

\author{
By Prof. T. S. WHEELER
}

$T$ HE honours degree courses in science in University College, Dublin, have recently been extended by one year so as to require four years of postmatriculation work. After three years, the student sits for a general degree examination in three subjects, and if he passes and attains an honours level in a subject is admitted to the honours school in that subject. A number of students, however, who wish to become chemists pass the general degree exam. ination at a level in chemistry insufficient to qualify for admission to the honours school. For those and for other students, who though qualified for honours study feel attracted towards industrial chemistry, there has been instituted a course which extends over one year and leads to a diploma in chemical tech. nology. To provide accommodation for the two types of fourth-year students two new chemical laboratories have been opened (see Nature, November 13 , p. 768), the Ryan Laboratory for honours degree students and the Nolan Laboratory for those taking chemical technology.

The Ryan Laboratory commemorates the late Prof. Hugh Ryan, who was professor of chemistry in the College during 1899-1931 and who initiated honours degree teaching there. The laboratory has a floor area of 460 sq. ft. and will accommodate up to ten students; as formal lectures to honours candidates are limited to five per week, a large proportion of the students' time is spent in the laboratory. There is no specialization between the three main branches of chemistry in the fourth year, and in the Ryan Laboratory normal advanced work in inorganic and organic chemistry is carried out; practical physical chemistry is done in a special laboratory. Emphasis is 
laid on quantitative inorganic analysis and on organic preparations involving modern methods of reduction, oxidation, condensation and so on. Short courses are also given on the application of semi-micro methods in both branches of chemistry. A reasonable variety of modern physico-chemical apparatus is available, the equipment including an absorptiometer (Spekker), a spectrophotometer (Coleman), microphotometer and spectroscope (Hilger), a chromatographic apparatus, an ultra-violet lamp and electrometric titration apparatus. A special feature is made of vacuum distillation; there are in the department molecular stills and various pumps, including a mercury pump combination (Towers) giving pressure of the order of 1 millibar. A laboratory fractionation column (Todd) has an efficiency of fifty theoretical plates. Each student gets an opportunity of making himself acquainted with the manipulation of the various pieces of apparatus.

The lecture courses and associated reading for the honours degree follow normal lines ; electronic theory may perhaps be regarded as a special feature. The students attend a series of lectures extending through. out the year in which the quantum mechanics of the hydrogen atom, bond formation, the periodic table and atomic structure, and applications of electron theory in organic chemistry are discussed in some detail. It has been found that the three-year general course, which includes physics and mathematics to a good pass-degree standard, is useful to the student in reading modern theoretical chemistry.

Students who obtain an honours degree may enter the research laboratories to work for the M.Sc. degre日; the work normally occupies one year. Various themes are studied; but at present the main work involves a study of the mechanism of base-catalysed reactions of the Claisen type with special reference to transformation reactions (see, for example, Proc. Roy. Dublin Soc., 24, 291 ; 1948).

The Nolan Laboratory (floor area 1,000 sq. ft.) is called after the late Prof. T. J. Nolan, who was professor of chemistry in the College during 1932-45. Prior to his comparatively early death, he had in conjunction with Prof. M. A. Hogan, professor of mechanical engineering, worked out the details of the course in chemical technology, but owing to the War was unable to make arrangements for the institution of the course. The laboratory contains apparatus to illustrate various unit chemical processes; this includes a centrifuge, a high-pressure (350 atmos. at $350^{\circ}$ ) autoclave of 5 litres capacity equipped with a stirring device and gas inlet (Cook), a 'Pyrex' glass fractionating column $3 \mathrm{ft}$. high, a steam-heated pan, a filter press, grinding equipment, high-temperature and vacuum ovens, and metering apparatus. Low.pressure steam and the other usual services are provided. The students receive lectures on the unit chemical operations which they study in the laboratory. At least half their time is spent in the Engineering Department of the College, where they have lecture courses on thermodynamics, materials of construction, workshop practice, fuel technology and electrotechnology. They also have practical instruction in the foundry, workshop, drawing office, and fuel and electrical laboratories.

In connexion with the planning of both the academic and industrial courses, it is desired to acknowledge valuable advice received from the heads of departments of a number of universities and colleges in Great Britain and from the Institution of Chemical Engineers.

\section{PREHISTORIC FLOODING IN THE SOMERSET LEVELS}

$T$ HE post-glacial history of the Somerset Levels has been the subject of considerable published work by Prof. H. Godwin and his collaborators in the pollen-analysis of peat; but a new series of "Studies of the Post-Glacial History of British Vegetation" reveals such a dramatic story as to appeal to more than specialists alone, although pollen-analysis and the study of macroscopical remains provide the scientific background of dating.

The unearthing and investigation of four distinct trackways through the raised bogs which lie between the Polden Hills and Wedmore Ridge are deseribed in the first paper by Prof. A. R. Clapham and Prof. Godwin (Phil. Trans. Roy. Soc. London, B, 233, $233-273$; 1948). Each is of particular interest, for, although appearing to be roughly contemporaneous, all represent different types of construction. The Meare Heath trackway is composed of transverse baulks of timber (mostly oak), many of which are perforated by mortise holes holding sharpened vertical piles. Long squared wooden stringers formed the margins of the track and indicate the use of wheeled traffic. The Shapwick Heath trackway, on the other hand, is of brushwood kept in place by stakes of various origins but including beech. Another trackway at Westhay is constructed from birch stems, the majority of which are laid longitudinally together with shaped, vertical stakes driven in to pin loose brushwood which prevented lateral displacement of the timbers. The shape of the axe-cuts on these timbers indicates a Late Bronze Age dating which is confirmed by other archæological remains. The Blakeway Farm trackway consists of overlapping faggots of very straight hazel poles which there is every reason to believe were derived from trees grown in a woodland system similar in its effects to present-day coppicing.

Each trackway was built upon the surface of a dry Sphagnum-Calluna bog; but in every case this appears to have been overwhelmed by flooding with the eventual formation of eutrophic Cladium fen. It is especially significant that they appear to have been submerged before suffering much hard wear, and a dramatic picture is drawn of the calamitous flooding of river-and lake-side colonies which caused a mass. evacuation over the improvised tracks.

The complementary paper bv Prof. Godwin (Phil. Trans. Roy. Soc. London, B, 233, 275-286; 1948) con. cerns the correlation between climate, forest. composition and prehistoric agriculture in the Somerset Levels. The most intense phases of agricultural activity appear to have occurred in the Middle and Late Bronze Ages and between Middle Iron Age and Middle Romano-British times, each being terminated by flooding of the raised bogs. Climatic change and not agricultural clearance is held to be the cause of changes in forest composition at the first flooding. The general nature of 'recurrence surfaces' is discussed, and it is pointed out that active bog-growth ceased in Romano-British times; but again this appears to have been the result of flooding by base-rich or brackish water and not an effect of Roman drainage schemes. The striking abundance of the remains of Scheuzeria palustris at the flooding surfaces contrasts strongly with its great scarcity at the present day (which is greater even than Prof. Godwin mentions, the species being extinct in 